\title{
A progressividade e o reajuste necessário na tabela do imposto de renda pessoa física ${ }^{1}$
}

\author{
The progressive and necessary adjustment in the table of personal income tax
}

\author{
Helio Massaoka ${ }^{2}$ \\ João Batista dos Reis ${ }^{3}$
}

\begin{abstract}
Resumo
Até 1988, mesmo sem determinação constitucional neste sentido, o IRPF era informado pelo critério da progressividade. Paradoxalmente, no ano em que foi promulgada a Constituição Federal de 1988, que constitucionalizou a obrigatoriedade de o imposto sobre a renda e proventos de quaisquer natureza ser informado pelo critério da progressividade, o legislador infraconstitucional operou mudanças radicais, diminuindo o número de alíquotas, bem como o percentual correspondente à alíquota máxima aplicável. Assim, a partir de 1989, as alíquotas aplicáveis ao IRPF passaram a ser apenas duas, comprometendo seriamente a progressividade do IRPF. Somado a isso, a falta do reajuste necessário na tabela do IRPF, tem acarretado problemas na regra-matriz de incidência fiscal, notadamente no conseqüente (prescritor), relativamente ao critério quantitativo (base de cálculo e alíquota).
\end{abstract}

Palavras Chave: Imposto de Renda Pessoa Física; Alíquota Progressiva; Critério Quantitativo da Regra-Matriz de Incidência.

\section{Abstract}

Until 1988, even without constitutional provision in this sense, the PIT was informed by the criterion of progressiveness. Paradoxically, in the year that the Federal Constitution was enacted 1988 to constitutionalize the obligation of the tax on income and earnings of any nature to be informed by the criterion of progressiveness, the legislature infra wrought radical changes, reducing the number of rates and as the percentage corresponding to the maximum applicable rate. Thus, since 1989, the rates that apply to the Income Tax became only two, seriously compromising the progressivity of the PIT. Added to this, lack of adjustment required in the PIT table, has caused problems in rule-array of tax incidence, especially in the consequent (prescriber), for the quantitative criterion (the tax base and tax rate).

\footnotetext{
${ }^{1}$ Trabalho apresentado como requisito parcial da nota referente ao 40 Bimestre, referente à disciplina de Direito Tributário, no curso de graduação em Direito, da Universidade Estadual de Londrina.

${ }^{2}$ Engenheiro Civil pela UEL, Analista Judiciário Área Administrativa do TRT - 9a Região, Pós-graduando em Direito do Trabal ho e Direito Processual do Trabalho pela UNIFIL, Acadêmico de Direito na UEL.

${ }^{3}$ Cabo do 30 Grupamento de Bombeiros da Polícia Militar do Paraná, em Londrina/PR, Acadêmico de Direito na UEL.
}

ReVista de Direito Púbuico, Londrina, V. 4, N. 1, P. 27-40, JAN/ ABR 2009. 
Keywords: Personal Income Tax, Progressive Tax Rate; Criteria Quantitative Rule-incidence matrix.

\section{Introdução}

Até 1988, mesmo sem determinação constitucional neste sentido, as alíquotas do Imposto de Renda Pessoa Física (IRPF) variavam de 0\% a 60\%, aplicadas progressivamente de acordo com o montante dos rendimentos tributáveis do contribuinte, podendo-se afirmar que até então o IRPF era informado pelo critério da progressividade, chegando a possuir 13 faixas/classes de renda no período de 1983 a 1985.

Paradoxalmente, no ano em que foi promulgada a Constituição Federal de 1988, estabelecendo no artigo 153, $\S 2^{\circ}$, inciso I, que o imposto sobre a renda e proventos de qualquer natureza "será informado pelos critérios da generalidade, da universalidade e da progressividade, na forma da lei", significando que a progressividade não ficou ao alvedrio do legislador. A Lei 7.713 de 22/12/1988 operou mudanças radicais, incluindo a diminuição do número de alíquotas, bem como do percentual correspondente à alíquota máxima aplicável.

Assim, a partir de 1989, as alíquotas aplicáveis ao IRPF passaram a ser apenas duas, sendo atualmente de $15 \%$ e $27,5 \%$, praticamente eliminando a progressividade do IRPF, em fragrante desrespeito ao mandamento constitucional.

\section{Regra-matriz da incidência tributária do IRPF}

Segundo os ensinamentos de Paulo de Barros Carvalho (2007, pp. 252-253), a norma tributária em sentido estrito é aquela que define a incidência fiscal, cujo resultado se apresenta na forma de um juízo hipotético condicional. Com efeito, a hipótese trará a previsão de um fato, enquanto a conseqüência prescreverá a relação jurídica (obrigação tributária) que vai se estabelecer onde e quando ocorrer o evento cogitado no suposto. Ou seja, a hipótese vislumbra um fato e a conseqüência prescreve os efeitos jurídicos que 0 acontecimento irá exalar, motivo pelo qual se fala em descritor e prescritor, o primeiro para designar 0 antecedente normativo e o segundo para indicar o seu conseqüente.

Assim, na hipótese (descritor), encontramos um critério material (comportamento de uma pessoa), condicionada no tempo (critério temporal), e no espaço (critério espacial). 
Na conseqüência (prescritor), deparamos com um critério pessoal (sujeito ativo e sujeito passivo) e um critério quantitativo (base de cálculo e alíquota).

Fixadas tais premissas, façamos a seguir a análise da Regra-Matriz da Incidência Tributária do IRPF.

\section{Critério material}

O critério material da regra-matriz da incidência tributária do IRPF, sempre fará referência a um fato, a um comportamento humano e será formado por um verbo, seguido de seu complemento. 0 comportamento humano que enseja a tributação pelo referido tributo dentre outros: 0 trabalho assalariado - efetuar aplicação financeira - alienar bem móvel ou imóvel - aplicar na bolsa de valores, (...). E o seu complemento é auferir renda e/ ou proventos de qualquer natureza. Adentrando no princípio da universalidade, o IR deve incidir sobre todas as rendas auferidas pelo contribuinte no período-base, respeitado igualmente o princípio da capacidade contributiva e excetuados os casos de isenção, os quais devem ser devidamente justificados em face dos princípios constitucionais.

Extrai-se da análise do artigo 153, inciso III, da Lei Maior, bem como do artigo 43, incisos I e II, do Código Tributário Nacional, que o critério material da regra-matriz de incidência do IRPF, é auferir renda e/ ou proventos de qualquer natureza.

\section{Critério espacial}

Por meio do critério espacial, investiga-se o local escolhido pela lei para a materialização do comportamento, ação ou conduta relevante para o tributo em questão.

Sem olvidar que o exame do critério espacial do IR não se confunde, como observa Paulo de Barros Carvalho (2007, p. 273), com o âmbito territorial de aplicação das leis, "alcançando não só os acontecimentos verificados no território nacional, mas até fatos, explicitamente tipificados, e que se compõem para além de nossas fronteiras".

Assim, inexistindo restrições na Carta Magna, o legislador ordinário infraconstitucional, possui liberdade para gravar rendimentos localizados no território nacional, ou ainda sujeitar à tributação do IR, em função do Princípio da Universalidade, rendimentos auferidos mundialmente, respeitando a soberania dos países, ou seja, não 
poderão ser gravados rendimentos de contribuintes que estão sob a égide de uma dada so berania tributária.

Destarte, é forçoso conclui-se que o critério espacial do IRPF consiste-se no território nacional, mesmo que a receita ou rendimento seja oriundo do exterior (art. $43, \S$ $2^{\circ}$, CTN).

\section{Critério temporal}

O exame do critério temporal possibilita o conhecimento da ocasião ou o átimo em que se considera concretizado o fato ou estado de fato, hipoteticamente descrito na lei.

Segundo Roque Antonio Carraza (2006, pp. 121-123), o IRPF é um tributo que nasce após haver transcorrido um determinado lapso de tempo e, essa periodicidade é o anocalendário.

Assim, de acordo com a melhor doutrina, o fato jurídico tributário ocorrerá sempre no último átimo de segundo do dia 31 de dezembro do ano-calendário que ocorreu a disponibilidade dos rendimentos. Data em que se consolida o fato jurídico tributário do Imposto de Renda da Pessoa Física.

\section{Critério pessoal}

Através do critério pessoal é possível identificar a pessoa que se posiciona na extremidade positiva do vínculo jurídico-tributário estabelecido, em decorrência de um fato hipoteticamente previsto na lei, e quais os critérios para designação da pessoa que se situa na extremidade negativa. A pessoa que se posiciona na extremidade positiva de um vínculo jurídico-tributário é o sujeito ativo. Por outro lado, a pessoa que se situa na extremidade negativa do mencionado vínculo é o sujeito passivo.

Assim sendo, nos termos do artigo 150, inciso III, do Texto Supremo, o sujeito ativo do IRPF é a União, sendo a Secretaria da Receita Federal o órgão responsável pela arrecadação e fiscalização do tributo.

Por outro lado, o sujeito passivo é a pessoa física que aufere a renda e/ou os proventos de qualquer natureza. No caso de imposto de renda retido na fonte, a fonte pagadora que não promover a retenção do tributo e o respectivo recolhimento funciona 
como responsável tributário, nos termos do parágrafo único do artigo 45 do CTN, ficando obrigada a pagar o respectivo tributo com recursos próprios.

\section{Critério quantitativo}

O critério encontra-se localizado no conseqüente da Regra-Matriz de Incidência Fiscal, compreendendo os institutos da base de cálculo e alíquota, através dos quais é possível a obtenção do montante devido a título de tributo devido ao sujeito ativo.

\section{Base de cálculo}

Leciona Paulo de Barros Carvalho (2007, pp. 341-342) que a base de cálculo "se destina, primordialmente, a dimensionar a intensidade do comportamento inserto no núcleo do fato jurídico, para que, combinando-se à alíquota, seja determinado o valor da prestação pecuniária".

A moderna doutrina do Direito Tributário admite duas funções básicas no instituto da base de cálculo. A primeira consiste em identificar a própria materialidade da hipótese de incidência. A segunda função seria a de quantificar o critério material da hipótese de incidência do tributo.

Desta forma, a base de cálculo do imposto devido é a diferença entre a soma dos rendimentos tributáveis recebidos durante 0 ano-calendário, exceto os isentos, nãotributáveis, tributáveis exclusivamente na fonte ou sujeitos à tributação definitiva, e as deduções permitidas pela legislação, conforme preceitua o artigo 80 da Lei № 9.250/95.

\section{Alíquota}

Conjugada à base de cálculo, a alíquota é um componente aritmético para a determinação do valor da prestação pecuniária a ser exigido do sujeito passivo.

As alíquotas podem ser: a) um valor numérico fixo, ou variável em função de escalas progressivas da base de cálculo; ou b) uma fração, percentual ou não, da base de cálculo. Sendo que as alíquotas em forma de fração pode ser proporcional invariável (a fração é invariável, seja qual for o seu valor monetário); proporcional progressiva (aumentando a 
base de cálculo, aumenta a proporção - caso do IRPF) ou proporcional regressiva (aumentando a base de cálculo, diminui a proporção).

A atual legislação brasileira prevê duas alíquotas para o IRPF:

Tabela 1 - Tabela Progressiva para o cálculo anual do IRPF para o exercício de 2008, ano-calendário de 2007.

\begin{tabular}{|c|c|c|}
\hline Base de cálculo anual em $\mathrm{R} \$$ & Alíquota \% & Parcela a deduzir do imposto em $\mathrm{R} \$$ \\
\hline Até $15.764,28$ & isento & - \\
\hline De $15.764,29$ até $31.501,44$ & 15,0 & $2.364,60$ \\
\hline Acima de $31.501,44$ & 27,5 & $6.302,28$ \\
\hline
\end{tabular}

OBS: tabela atualizada pela Medida Provisória no 340, de 29 de dezembro de 2006.

\section{Considerações acerca da alíquota progressiva do IRPF}

Observa Hugo de Brito M achado (2006, p. 332) a propósito da progressividade do IR que, curiosamente, a alíquota era, ao menos para as pessoas físicas, progressivo sem que houvesse determinação constitucional neste sentido (ver tabela 3).

O Texto Magno de 1988 estabeleceu no artigo 153, § 2으, inciso I, que o imposto sobre a renda e proventos de qualquer natureza "será informado pelos critérios da generalidade, da universalidade e da progressividade, na forma da lei", significando que a progressividade passou a ser obrigatória para o legislador. Paradoxalmente, no mesmo ano, a Lei 7.713 de 22/12/1988, praticamente eliminou a progressividade do IRPF, estabelecendo apenas duas alíquotas, em fragrante desrespeito ao mandamento constitucional.

Certifica Vittorio Cassone (2004, p. 202-203) que "no momento em que o legislador infraconstitucional vai exercer essa competência (para definir o fato gerador - tecnicamente, hipótese de incidência), o fará com certa margem de discricionariedade, embora em grau mínimo".

Assim, a confecção da tabela do IRPF seria um exemplo de situação em que 0 legislador poderia exercer essa discricionariedade legislativa, norteando-se pelos princípios da proporcionalidade e da razoabilidade, sempre conforme a regra-matriz de incidência que a Carta Suprema estabelece.

Ives Gandra da Silva Martins (1998, p. 51) assevera que, "no direito tributário, os princípios da capacidade contributiva e da redistribuição da renda estão na própria essência do direito estrutural". Compreendendo-se por capacidade contributiva a potencialidade do 
sujeito passivo de agregar ao patrimônio e necessidades do Erário, recursos que não afetem a própria capacidade de gerá-los, sob pena de a tributação se transformar em confisco. Entendendo, por outro lado, como função redistributiva de riqueza aquela que permite que outras pessoas atinjam capacidade contributiva, sem prejudicar a capacidade contributiva daqueles que os criou.

Progressividade da alíquota do irpf no direito comparado

Segundo a PRICEWATERHOUSECOOPERS (Information Guide Series - Worldwide Summaries 1999-2000), a progressividade, para o ano de 1999, apresentou as seguintes alíquotas para o IRPF:

\begin{tabular}{|c|c|}
\hline \multicolumn{2}{|c|}{ Alíquotas de IRPF em outros países } \\
\hline PAÍs & ALÍQUOTA - IRPF \\
\hline Austrália & $17 \%$ a $47 \%$ \\
\hline Áustria & $10 \%$ a $50 \%$ \\
\hline Argentina & $6 \%$ a $35 \%$ \\
\hline Alemanha & $23,9 \%$ a $53 \%$ \\
\hline Bélgica & $25 \%$ a $55 \%$ \\
\hline Canadá & $17 \%$ a $29 \%$ \\
\hline Chile & $5 \%$ a $45 \%$ \\
\hline Dinamarca & $24 \%$ a $33 \%$ \\
\hline Espanha & $18 \%$ a $48 \%$ \\
\hline EUA & $15 \%$ a $39,6 \%$ \\
\hline França & $5 \%$ a $56,8 \%$ \\
\hline Finlândia & $5,5 \%$ a $38 \%$ \\
\hline Inglaterra & $10 \%$ a $40 \%$ \\
\hline Itália & $19 \%$ a $46 \%$ \\
\hline Japão & $10 \%$ a $50 \%$ \\
\hline Portugal & $15 \%$ a $40 \%$ \\
\hline Polônia & $19 \%$ a $49 \%$ \\
\hline
\end{tabular}


No estudo do direito, é útil recorrer a sistemas alienígenas para acentuar as peculiaridades. Analisando-se as alíquotas supra é exacerbada a diferença de progressividade se comparado com as vigentes no Brasil. A maioria dos países adota alíquotas altas, sendo que as alíquotas máximas giram em torno de $50 \%$, enquanto que no Brasil, a máxima é $27,5 \%$.

Mister se faz restabelecer o princípio da progressividade da tabela do IRPF, que foi totalmente desnaturado com a redução das alíquotas nos últimos anos. De 1983 a 1985, 0 Brasil possuía 13 faixas/classes de renda e as alíquotas variavam de 5\% a 60\%. A partir de 1997, restaram apenas duas alíquotas, a mínima de 15\% e a máxima de 27,5\% (ver tabela 3). Esses dados corroboram o sentimento da população de que são apenas os assalariados que arcam com o gravame tributário no Brasil.

\begin{tabular}{|c|c|c|}
\hline \multicolumn{2}{|c|}{ Tabela 3 } \\
\hline \multicolumn{2}{|c|}{ Alíquotas de IRPF no Brasil } \\
\hline Período de vigência & $\begin{array}{c}\text { Quantidade de classes } \\
\text { de renda (faixas) }\end{array}$ & Alíquotas \\
\hline 1979 a 1982 & 12 & $0 \%$ a $55 \%$ \\
\hline 1983 a 1985 & 13 & $0 \%$ a $60 \%$ \\
\hline 1986 a 1987 & 11 & $0 \%$ a $45 \%$ \\
\hline 1988 & 9 & $10 \%$ e $25 \%$ \\
\hline 1989 a 1991 & 2 & $15 \%$ e $25 \%$ \\
\hline 1992 & 2 & $15 \%$ a $35 \%$ \\
\hline 1995 & 3 & $15 \%$ e $25 \%$ \\
\hline 1996 a 1997 & 2 & $15 \%$ e $27,5 \%$ \\
\hline Fonte: Regulamento do Imposto de Renda & 2007 & \\
\hline
\end{tabular}

A tabela 3 ratifica a quase inexistência da progressividade no Brasil, sendo uma questão de determinação política, conduzida na contramão da justiça fiscal e da Constituição.

Entretanto, Paulo Ayres de Barreto (2001, p. 95) efetua as seguintes refutações: “é tradição no direito brasileiro, na definição da alíquota do IRPF, a estipulação da chamada parcela a deduzir. Assim, se conjugarmos alíquota e parcela a deduzir surgem, ao lado da alíquota nominal, as alíquotas efetivas, aplicáveis a cada caso concreto, evidenciando a inequívoca progressividade". 
Destarte, a alíquota efetiva do IRPF é de 0,00\% a 27,5\%, demonstrando, segundo Paulo Ayres de Barreto, que o legislador não deixou de atender ao comando da Lei Magna, pois a parcela a deduzir - esconde a alíquota efetiva incidente sobre o IRPF, conforme demonstra a tabela 4.

Tabela 4 - Cálculo da alíquota efetiva para o ano-calendário 2007.

\begin{tabular}{|c|c|c|c|c|c|c|}
\hline Faixas & Salário (R\$) & Alíquota & Imposto & Redutor & Imposto efetivo & \begin{tabular}{|c|}
$\begin{array}{c}\text { Alíquota } \\
\text { efetiva }\end{array}$ \\
\end{tabular} \\
\hline \multirow{5}{*}{$\begin{array}{c}\text { Até RS } \\
1.313,69\end{array}$} & $R \$ 380,00$ & $0,00 \%$ & $R \$ 0,00$ & $\mathrm{R} \$ 0,00$ & RS 0,00 & $0,00 \%$ \\
\hline & $\mathrm{R} \$ 600,00$ & $0,00 \%$ & $\mathrm{R} \$ 0,00$ & $\mathrm{R} \$ 0,00$ & RS 0,00 & $0,00 \%$ \\
\hline & R\$ 900,00 & $0,00 \%$ & $\mathrm{R} \$ 0,00$ & R\$ 0,00 & RS 0,00 & $0,00 \%$ \\
\hline & RS $1.200,00$ & $0,00 \%$ & R\$ 0,00 & $\mathrm{R} \$ 0,00$ & RS 0,00 & $0,00 \%$ \\
\hline & RS $1.300,00$ & $0,00 \%$ & $\mathrm{R} \$ 0,00$ & $\mathrm{R} \$ 0,00$ & RS 0,00 & $0,00 \%$ \\
\hline \multirow{4}{*}{$\begin{array}{c}\text { DeRS } \\
1.313,70 \text { à } \\
\text { R\$2 } 2.625,12\end{array}$} & RS $1.500,00$ & $15,0 \%$ & RS 225,00 & RS 197,05 & RS 27,95 & $1,86 \%$ \\
\hline & RS $1.800,00$ & $15,0 \%$ & RS 270,00 & RS 197,05 & RS 72,95 & $4,05 \%$ \\
\hline & RS $2.100,00$ & $15,0 \%$ & RS 315,00 & RS 197,05 & $\mathrm{R} \$ 117,95$ & $5,62 \%$ \\
\hline & RS $2.400,00$ & $15,0 \%$ & RS 360,00 & RS 197,05 & $\mathrm{R} \$ 162,95$ & $6,79 \%$ \\
\hline \multirow{12}{*}{$\begin{array}{c}\text { De } R \$ \\
2.625,13 \mathrm{em} \\
\text { diante }\end{array}$} & RS $2.700,00$ & $27,5 \%$ & RS 742,50 & RS 525,19 & R\$ 217,31 & $8,05 \%$ \\
\hline & RS $3.000,00$ & $27,5 \%$ & RS 825,00 & RS 525,19 & $\mathrm{R} \$ 299,81$ & $9,99 \%$ \\
\hline & RS $3.500,00$ & $27,5 \%$ & RS 962,50 & RS 525,19 & $\mathrm{R} \$ 437,31$ & $12,49 \%$ \\
\hline & RS $4.000,00$ & $27,5 \%$ & R\$ $1.100,00$ & RS 525,19 & R\$ 574,81 & $14,37 \%$ \\
\hline & RS $5.000,00$ & $27,5 \%$ & R\$ $1.375,00$ & RS 525,19 & R\$ 849,81 & $17,00 \%$ \\
\hline & RS 7.000,00 & $27,5 \%$ & R\$ $1.925,00$ & RS 525,19 & R\$ $1.399,81$ & $20,00 \%$ \\
\hline & $\mathrm{R} \$ 10.000,00$ & $27,5 \%$ & R\$ $2.750,00$ & RS 525,19 & $\mathrm{R} \$ 2.224,81$ & $22,25 \%$ \\
\hline & $\mathrm{R} \$ 15.000,00$ & $27,5 \%$ & R\$ $4.125,00$ & RS 525,19 & $\mathrm{R} \$ 3.599,81$ & $24,00 \%$ \\
\hline & $\mathrm{R} \$ 20.000,00$ & $27,5 \%$ & R\$ $5.500,00$ & RS 525,19 & $\mathrm{R} \$ 4.974,81$ & $24,87 \%$ \\
\hline & $\mathrm{R} \$ 30.000,00$ & $27,5 \%$ & $\mathrm{R} \$ 8.250,00$ & RS 525,19 & $\mathrm{R} \$ 7.724,81$ & $25,75 \%$ \\
\hline & $\mathrm{R} \$ 50.000,00$ & $27,5 \%$ & $\mathrm{R} \$ 13.750,00$ & RS 525,19 & $\mathrm{R} \$ 13.224,81$ & $26,45 \%$ \\
\hline & R\$ $100.000,00$ & $27,5 \%$ & $\mathrm{R} \$ 27.500,00$ & RS 525,19 & $\mathrm{R} \$ 26.974,81$ & $26,97 \%$ \\
\hline
\end{tabular}

Entretanto, embora o legislador tenha observado a progressividade, não deixa de merecer crítica no que se refere ao limite de $27,5 \%$, por não concretizar efetivamente 0 princípio da capacidade contributiva.

\section{0 reajuste necessário na tabela do IRPF}

No período de 1996 a 2001, a tabela do IRPF ficou congelada. A partir da campanha conduzida pelo UNAFISCO SINDICAL - Sindicato dos Auditores Fiscais da Receita Federal 
("Chega de Confisco", lançada em 2000) foi aprovada a Lei 10.451/2002, que corrigiu em 17,5\% a tabela do IRPF. Em 2005, a tabela foi corrigida em 10\% (Lei 11.119/2005).

Desta forma, a correção de $8 \%$ na tabela do IRPF, válida a partir de 1ํ de fevereiro de 2006, não repôs integralmente os efeitos da inflação no pagamento de IR.

As correções foram apenas parciais e não refletiram toda a inflação do período. A inflação de janeiro/1996 a janeiro/2006, apurada pelo Índice de Preço ao Consumidor Amplo (IPCA/IBGE), foi de 104,98\%. Descontando os reajustes já concedidos de 17,5\% (2002), de $10 \%$ (2005) e de $8 \%$ (2006), a tabela do IR, ainda, precisa ser corrigida em 50,52\% (ver tabela $5)$.

Tabela 5

\begin{tabular}{|c|c|c|}
\hline \multicolumn{3}{|c|}{ Tabela 5} \\
\hline \multicolumn{3}{|c|}{ Proposta de Reajuste da Tabela Progressiva IRPF } \\
\hline & Tabela atual & Como deveria ser \\
\hline Alíquotas e Limites & $\begin{array}{l}\text { (dezembro de } 2006) \\
\text { (com correção de } 8 \% \text { ) }\end{array}$ & $\begin{array}{l}\text { Reajuste necessário - jan/1996 a } \\
\text { dez/2006 50,52\% (IPCA) }\end{array}$ \\
\hline Isento & Até $\mathrm{R} \$ 1.257,12$ & Até $\mathrm{R} \$ 1.892,22$ \\
\hline $15 \%$ & $\begin{array}{l}\text { De } R \$ 1.257,13 \\
\text { até } R \$ 2.512,08\end{array}$ & $\begin{array}{l}\text { De R\$ } 1.892,23 \\
\text { até } \mathrm{R} \$ 3.781,23\end{array}$ \\
\hline $27,50 \%$ & Acima de $\mathrm{R} \$ 2.512,08$ & Acima de $\mathrm{R} \$ 3.781,23$ \\
\hline $\begin{array}{l}\text { Limite da dedução } \\
\text { por dependente ao mês }\end{array}$ & $\begin{array}{l}\mathrm{R} \$ 126,36 \\
\text { por dependente }\end{array}$ & $\begin{array}{l}\mathrm{R} \$ 190,18 \\
\text { por dependente }\end{array}$ \\
\hline $\begin{array}{l}\text { Limite da dedução com despesas } \\
\text { de educação ao ano }\end{array}$ & $\mathrm{R} \$ 2.373,84$ & $\mathrm{R} \$ 3.573,10$ \\
\hline \multicolumn{3}{|c|}{ Nota: Inflação de Dez/06 estimada em 0,45\% (Boletim Focus, BACEN) } \\
\hline \multicolumn{3}{|c|}{ Elaboração: Departamento de Estudos Técnicos do Unafisco Sindical } \\
\hline
\end{tabular}

A falta da correção integral da tabela do Imposto de Renda vem provocando uma sobretaxação, recaindo de forma mais grave sobre os salários mais baixos.

A Medida Provisória 340, de 29/12/2006, convertida em Lei ㄲo 11.482, de 31/05/2007, efetuou alterações na tabela do IRPF, corrigindo em 4,5\% a tabela do IRPF para o ano-calendário 2007, determinando ainda a aplicação sucessiva do mesmo índice até o ano-calendário 2010, o que certamente provocará uma defasagem ainda maior.

A tabela 6, elaborada pelo Departamento de Estudos Técnicos do Unafisco Sindical, demonstra que um trabalhador com renda mensal de $\mathrm{R} \$ 2.000,00$ pagou, em $2005, \mathrm{R} \$$ $1.108,80$ de IR, quando deveria ter pagado apenas $\mathrm{R} \$ 78,59$, se a tabela tivesse sido corrigida pela variação integral do IPCA - uma tributação a maior de 1.310,87\%. Enquanto, um trabalhador com renda mensal de $\mathrm{R} \$ 10.000,00$ teve uma tributação a maior de $11,58 \%$, no 


\begin{tabular}{|c|c|c|c|c|c|}
\hline \multicolumn{6}{|c|}{ Tabela 7} \\
\hline \multicolumn{6}{|c|}{ Limite de Isenção do Imposto de Renda em Salários Mínimos } \\
\hline $\begin{array}{c}\text { Ano } \\
\text { (exercício) }\end{array}$ & $\begin{array}{l}\text { Salário Mínimo } \\
\text { (SM) } \\
\text { Mensal R\$ (1) }\end{array}$ & $\begin{array}{l}\text { SM Corrigido } \\
\text { Pelo IPCA }\end{array}$ & $\begin{array}{c}\text { Limite } \\
\text { Isenção } \\
\mathrm{R} \$ \text { mensal (2) }\end{array}$ & $\begin{array}{l}\text { Limite de } \\
\text { Isenção } \\
\text { em SM }\end{array}$ & $\begin{array}{c}\text { Limite de Isenção em } \\
\text { SM } \\
\text { sem aumento Real }\end{array}$ \\
\hline & (a) & (b) & (c) & $(\mathrm{d})=(\mathrm{c}) /(\mathrm{a})$ & $(\mathrm{e})=(\mathrm{c}) /(\mathrm{b})(3)$ \\
\hline 1995 & 70,00 & 70,00 & 733,62 & 10,48 & 10,48 \\
\hline 1996 & 100,00 & 81,50 & 900,00 & 9,00 & 11,04 \\
\hline 1997 & 112,00 & 97,12 & 900,00 & 8,04 & 9,27 \\
\hline 1998 & 120,00 & 105,46 & 900,00 & 7,50 & 8,53 \\
\hline 1999 & 130,00 & 109,52 & 900,00 & 6,92 & 8,22 \\
\hline 2000 & 136,00 & 116,45 & 900,00 & 6,62 & 7,73 \\
\hline 2001 & 151,00 & 123,42 & 900,00 & 5,96 & 7,29 \\
\hline 2002 & 180,00 & 131,68 & 1058,00 & 5,88 & 8,03 \\
\hline 2003 & 200,00 & 152,28 & 1058,00 & 5,29 & 6,95 \\
\hline 2004 & 240,00 & 161,84 & 1058,00 & 4,41 & 6,54 \\
\hline 2005 & 300,00 & 174,91 & 1164,00 & 3,88 & 6,65 \\
\hline \multicolumn{6}{|c|}{ Fonte: Secretaria da Receita Federal e Dieese. } \\
\hline \multicolumn{6}{|c|}{ Elaboração: Departamento de Estudos Técnicos do Unafisco Sindical } \\
\hline \multicolumn{6}{|c|}{$\begin{array}{l}\text { Notas: } \\
\text { (1) Valores vigentes em } 31 \text { de dezembro de cada ano base. Os valores têm como fonte } \\
\text { Dieese - Anuário dos Trabalhadores } 2005 \text {. } \\
\text { (2) A tabela do Imposto de Renda no período de } 1993 \text { a } 1995 \text { tinha como limite de isenção o valor de } \\
\text { 12.000 Ufirs. O valor foi convertido para R } \$ \text { multiplicado pela Ufir de } 31 / 12 / 94=0,6618 \\
\text { (3) Limite de isenção em quantidades de Salários Mínimos, desconsiderando os aumentos reais. }\end{array}$} \\
\hline
\end{tabular}

As deduções permitidas e o reajuste necessário

As deduções permitidas pela legislação brasileira são ínfimas e se encontram totalmente defasadas, segundo estudos elaborados pelo UNAFISCO SINDICAL - Sindicato dos Auditores Fiscais da Receita Federal:

- Dependentes: o contribuinte pôde, em 2006, deduzir $R \$ 1.516,32$ por dependente, 0 que corresponde ao valor mensal de irrisórios $R \$ 126,36$, insuficientes para cobrir os gastos com o dependente (assistir, criar e educar). Sendo urgente repor a inflação do período, mormente, corrigindo este valor para $R \$ 2.226,56$, além de aumentá-lo em termos reais.

- Educação: a dedução das despesas com educação sofreu limitações ao longo dos últimos anos e em 2006 puderam ser deduzidos apenas os pagamentos do ensino formal, dos cursos de especialização e de outros cursos profissionalizantes. A parcela dedutível em 2006 foi de $\mathrm{R} \$ 2.373,84$ por dependente e/ou pelo próprio contribuinte. Só para repor a inflação, torna-se necessária a correção deste valor para $R \$ 3.485,75$. Além disso, é 
imprescindível que se volte a permitir a dedução de outros gastos como cursos de idiomas, material escolar, uniforme escolar e outros encargos correlatos.

- Saúde: embora não exista limite para a dedução das despesas com saúde, a legislação atual do Imposto de Renda é restringente, não permitindo a dedução de gastos com medicamentos, exceto aqueles fornecidos pelo próprio estabelecimento hospitalar.

- Moradia: até 1988, era permitida a dedução das despesas com moradia, tais como aluguel e juros de financiamento da casa própria. É importante que se volte a deduzir do Imposto de Renda a despesa com moradia.

\section{Conclusão}

À guisa de conclusão, além da correção da tabela do IRPF e das deduções, é importante criar mecanismos para assegurar a isonomia tributária entre as diferentes espécies de rendimentos, colimando o princípio da capacidade contributiva. É extremamente injusta a legislação atual que submete à tabela progressiva somente os rendimentos do trabalho, enquanto os rendimentos do capital são tributados exclusivamente na fonte, não sujeitos à progressividade, e acabam sendo tributados apenas proporcionalmente, e com alíquotas inferiores, mantendo o vetusto arcabouço tributário.

Um outro exemplo de favorecimento da renda do capital é a isenção do Imposto de Renda na Fonte sobre os lucros e dividendos distribuídos aos acionistas, enquanto os lucros distribuídos aos trabalhadores são tributados na tabela progressiva do IRPF.

Trata-se de privilégios em função da origem da renda (capital) e nada os justifica. A Constituição brasileira definiu a capacidade contributiva como instrumento para graduar os impostos, não podendo jamais ser em função da origem ou da natureza da renda.

Essa forma de tributação contribui para aumentar, ainda mais, a vergonhosa e ingente concentração de renda. Portanto, é preciso mudar a legislação infraconstitucional para sujeitar todos os rendimentos (do trabalho e do capital) à tabela progressiva, resgatando a efetiva progressividade no IRPF, garantindo a isonomia entre os diferentes rendimentos e corrigir a tabela do IRPF, assim como mudar as alíquotas e as regras das deduções. 


\section{Referências}

BARRETO, Paulo Ayres, Imposto de Renda e Preços de Transferência. São Paulo: Editora Dialética, 2001.

CARRAZA, Roque Antonio, Imposto sobre a Renda - perfil constitucional e temas específicos, 2a edição, São Paulo: Malheiros Editores Ltda, 2006.

CARVALHO, Paulo de Barros, Curso de Direito Tributário, 18a edição, São Paulo: Editora Saraiva, 2007.

CASSONE, Vittorio, Interpretação no Direito Tributário - teoria e prática, São Paulo: Editora Atlas, 2004.

M ACHADO, Hugo de Brito, Curso de Direito Tributário, 27ạ edição, São Paulo: Malheiros Editores Ltda, 2006.

M ARTINS, Ives Gandra da Silva, Teoria da Imposição Tributária, 2ạ edição, São Paulo: LTr, 1998.

UNAFISCO SINDICAL - Sindicato Nacional dos Auditores Fiscais da Receita Federal - Depto. de Estudos Técnicos, Estudos sobre a necessidade de atualização da Tabela do IRPF, disponível em: http://www.unafisco.org.br/, acesso em 04/11/2007. 